\title{
Chemokine Coreceptor-2 Gene Polymorphisms among HIV-1 Infected Individuals in Kenya
}

\author{
Dorcas Wachira, Raphael Lihana, Vincent Okoth, \\ Alex Maiyo, and Samoel Ashimosi Khamadi \\ Kenya Medical Research Institute, Nairobi 54628, Kenya \\ Correspondence should be addressed to Samoel Ashimosi Khamadi; skhamadi@gmail.com
}

Received 16 June 2015; Accepted 21 July 2015

Academic Editor: Giuseppe Murdaca

Copyright (c) 2015 Dorcas Wachira et al. This is an open access article distributed under the Creative Commons Attribution License, which permits unrestricted use, distribution, and reproduction in any medium, provided the original work is properly cited.

\begin{abstract}
Chemokine Coreceptor-2 (CCR2) is an entry coreceptor for HIV-1. A mutation in the coding gene for this coreceptor, CCR2-64I, has been shown to be an important factor for delaying disease progression. In Kenya no studies have been done to determine the status of CCR2 gene polymorphisms among HIV-1 infected individuals. To determine the existence and distribution of CCR2 gene mutations and identify polymorphic groups of the coreceptor gene in the population, a cross-sectional study was conducted to analyze the differences in allelic frequencies of CCR2-64I among HIV-1 seropositive individuals. Blood samples were collected from HIV/AIDS screening centers and analyzed for the presence of CCR2-64I using restriction fragment length polymorphism (RFLP). One hundred and eighteen samples collected from different regions of the country were genotyped for the CCR2-64I mutation. Of these, $4(3.4 \%)$ were homozygous mutants (I/I) and $21(17.8 \%)$ were heterozygous (V/I). Ninety-three subjects $(78.8 \%)$ were wild type $(\mathrm{V} / \mathrm{V})$. With the search for a preventive/therapeutic HIV vaccine elusive, the presence of CCR-2 gene polymorphisms that delay disease progression and prolong the lives of the infected in the Kenyan population may contribute to the growing evidence that host genetic factors are important in predicting susceptibility to HIV-1 infection.
\end{abstract}

\section{Introduction}

The natural history and pathogeneses of the human immunodeficiency virus type 1 (HIV-1) infections are characterized by many viral and host factors and their interactions. First, entry of HIV-1 into target cells requires both CD4 and one of the chemokine receptors. Two chemokine receptors, chemokine (C-C motif) receptor 5 (CCR5) and chemokine (C-X-C motif) receptor 4 (CXCR4), are the major coreceptors for macrophage-cell-tropic (M-tropic or R5-tropic) and T-cell-tropic (T tropic or X4-tropic) HIV-1 infection, respectively [1]. Other chemokine receptors, CCR2, CCR3, CCR8, CCR9, CX(3)CR1, CXCL12 (SDF1), and CCL5 (RANTES), can act as alternative coreceptors for mediating some strains of HIV-1 infection. Genetic variants of these genes, which encode HIV-1 coreceptors and their ligands, have been implicated in the susceptibility to HIV-1 infection, and their prevalence varies by ethnicity.

Polymorphisms of the genes for CCR5 (CCR5-Delta32), CCR2, and stromal-derived factor 1 (SDF1) have been found to modulate the susceptibility of individuals to HIV-1 infection and/or the pathogenic progression [2]. The CCR5 32 polymorphism encoding a 32-base pair deletion in the CCR5 coding region has been shown to result in a nonfunctional truncated protein [2]. Multiple studies have confirmed the protective impact of CCR $5 \Delta 32$ on HIV disease and have identified additional CCR5 polymorphisms that alter disease progression $[3,4]$.

The CCR2 allele is a prominent receptor for the monocyte chemoattractant protein (MCP) group of $\mathrm{C}-\mathrm{C}$ chemokines and is among the most important genetic factors known to be associated with host resistance to HIV-1 infection. A point mutation in the CCR2 gene that leads to a single, conservative amino acid change, which substitutes isoleucine for valine at position 64 (CCR2-64I), in the first transmembrane domain of CCR2 has been found to correlate significantly with delayed progression to acquired immunodeficiency syndrome (AIDS) [5].

Studies have also shown that homozygosity for this mutation is associated with a delayed progression to disease, while 
individuals who are heterozygous for CCR2-64I progress quickly to AIDS $[6,7]$. Thus, polymorphisms in chemokine ligands and receptors may further impact disease acquisition and progression by mechanisms beyond viral entry.

The frequency of the CCR2-64I mutation varies in different ethnic populations. Several studies have shown that the CCR2-64I allele is broadly distributed in humans. The frequency of this polymorphism was $50 \%$ in the HIV-infected but long-term nonprogressors (LTNPs) Chinese but only 23\% in typical progressors. This suggests that the high frequency of CCR2-64I allele is associated with a slower progression to AIDS [7].

In spite of the importance of chemokine receptors in AIDS pathogenesis, little information is available on the frequency of chemokine receptor gene polymorphisms modulating HIV-1 infection in the Kenyan population. This study was carried out to identify variants of the CCR2 gene among HIV/AIDS clients as the frequency of these genetic variants in Kenya, particularly in HIV-1 seropositive and/or seronegative high-risk populations, is currently unknown. Understanding how these genetic variants contribute to susceptibility to HIV-1 infection and disease progression could add to the existing knowledge on HIV pathogenesis.

\section{Materials and Methods}

2.1. Study Samples. After receiving informed consent from the clients, a total of 118 blood samples from HIV-1 infected participants in 8 provincial and district hospitals were collected in EDTA tubes. Five $\mathrm{mL}$ of blood was drawn from each client. Demographic data such as age, gender, and residence were obtained using a self-reporting questionnaire. The research work was approved by the Graduate School Board of Kenyatta University (reference I56/13034/05). The study was conducted according to the national and international regulations governing the use of human subjects in biomedical research.

2.2. Laboratory Procedures. Peripheral blood mononuclear cells (PBMCs) were obtained from $5 \mathrm{~mL}$ of whole blood by density gradient centrifugation using Ficoll-Paque Plus as per the manufacturer's guidance. Briefly, whole blood was added to $15 \mathrm{~mL}$ of PBS buffer ph 7.2 containing $2 \mathrm{mM}$ EDTA and chilled to $2-8^{\circ} \mathrm{C}$. This mixture was layered carefully over $15 \mathrm{~mL}$ of Ficoll-Paque in a $50 \mathrm{~mL}$ falcon tube. This was centrifuged at $400 \times \mathrm{g}$ for 30 minutes at $20^{\circ} \mathrm{C}$ in a swingingbucket rotor without brakes. The upper layer was aspirated leaving the PBMC mononuclear cell layer undisturbed. This layer was transferred to a new tube and mixed with the PBS buffer mentioned above and span at $300 \times \mathrm{g}$ for 10 minutes to clean the mononuclear cells. DNA was extracted from the cells using DNAzol and ethanol precipitation.

Amplification of a 128-base pair fragment of the CCR2 gene was carried out using CCR2 gene primers CKR2_1A (sense): 5' TTG TGG GCA ACA TGA TGG and CKR2_1Z (antisense): $5^{\prime}$ GAG CCC ACA ATG GGA GAG TA in a reaction mixture containing $10 \mathrm{pmol}$ of each primer, $2 \mu \mathrm{L}$ of extracted DNA, and a commercial PCR master mix. After an initial denaturation step at $94^{\circ} \mathrm{C}$ for 5 minutes, PCR was run for 40 cycles of $94^{\circ} \mathrm{C}$ for 1 minute, $55^{\circ} \mathrm{C}$ for 1 minute, and $72^{\circ} \mathrm{C}$ for 1 minute. The resulting amplicons were digested with $B s a B I$ restriction enzyme at $60^{\circ} \mathrm{C}$ for 2 hours. The products were then electrophoresed on a $4 \%$ agarose gel and stained with ethidium bromide for visualization. A $128 \mathrm{bp}$ fragment indicated a homozygous wild genotype, while $110 \mathrm{bp}$ and $18 \mathrm{bp}$ fragments were indicative of the homozygous mutant genotype. The presence of three fragments revealed the heterozygous genotype.

2.3. Statistical Analysis. Genotype frequencies were evaluated using the Hardy-Weinberg equilibrium test. Allele frequencies and the prevalence of genotypes were determined using the $\chi^{2}$ test. Statistical significance was defined as $P \leq$ 0.05 .

\section{Results}

A total of 118 samples were collected and analyzed. Among these, 4 (3.4\%) had the CCR2-V64I homozygous mutation A/A while 21 (17.8\%) had the heterozygous mutation G/A. Distribution of the wild type gene in the provinces ranged from $93.3 \%$ in Nairobi to $69.2 \%$ in Coast province. Nyanza province had the highest heterozygous mutations (25\%) followed by Central, Coast, North Eastern, and Rift Valley provinces with all three having approximately $22 \%$, while Nairobi province had the lowest (6.7\%). A single case of homozygous mutations was present in only four provinces (Table 1). There were however no significant differences in the distribution of CCR2-V641 mutations across the provinces $(P=0.98)$. Within the provinces, there was a significant difference in the distribution of G/A mutations compared to A/A mutations $(P<0.001)$. Generally, the allelic genotypic frequency of the CCR2-V64I in all the eight provinces was below $8 \%$ of the samples analyzed.

\section{Discussion}

The prevalence of the mutant homozygous and heterozygous CCR2-64-I alleles was significant considering the small number of samples that were analyzed. This is as expected considering that mutations occur at low levels in populations. The significantly high CCR2-64-I mutations in the sampled population could be an indication that the mutation is common in the population. It could also suggest that this is an established mutation that has been passed down through generations even before the advent of the HIV/AIDS scourge. Similar studies have been carried out in other populations that show a significantly high distribution of the CCR2-64I allelic mutations [8]. In a study in Moscow in 2001, for example, the wild type CCR2 gene alleles were $77.87 \%$ with the rest being CCR2-64-I heterozygotes without any CCR264-I mutant homozygotes [5]. In a similar study in Brazil in 2002 , it was observed that the frequency of the CCR2 wild type genotype was $60 \%$ while that of the heterozygous mutant genotype was $44 \%$ while the homozygous mutant genotype was 3\% [9]. In a similar study carried out in Kenya in 1998, it was observed that frequency of the CCR2-64I allele was 23\% 
TABLE 1: Summary of CCR2 gene polymorphisms in each of the 8 provinces of Kenya.

\begin{tabular}{lllll}
\hline & & & \\
CCR2 & CCR2 & CCR2 & Total \\
Province & G/G (wt/wt) & G/A (wt/mut) & A/A (mut/mut) & $N$ \\
& $n(\%)$ & $n(\%)$ & $n(\%)$ & $\mathbf{1 4}$ \\
\hline Central & $11(78.6)$ & $3(21.4)$ & - & $\mathbf{1 3}$ \\
Coast & $9(69.2)$ & $3(23)$ & - & $\mathbf{1 5}$ \\
Eastern & $13(86.7)$ & $2(13.3)$ & - & $\mathbf{1 5}$ \\
Nairobi & $14(93.3)$ & $1(6.7)$ & $1(6.7)$ & $\mathbf{1 5}$ \\
North Eastern & $11(73.3)$ & $3(20)$ & - & $\mathbf{1 6}$ \\
Nyanza & $12(75)$ & $4(25)$ & $1(6.3)$ & $\mathbf{1 6}$ \\
Rift Valley & $12(75)$ & $3(18.8)$ & $1(7.1)$ & $\mathbf{1 4}$ \\
Western & $11(78.6)$ & $2(14.3)$ & $\mathbf{4}$ & $\mathbf{1 1 8}$ \\
Total & $\mathbf{9 3}$ & $\mathbf{2 1}$ & & \\
\hline
\end{tabular}

in a cohort of commercial sex workers [1]. This is comparable to what was seen in this study though there were variations within the different provinces of Kenya.

The CCR2-V64I mutation affects the gene that encodes the CCR2 receptor on the outside of cells and is more common than the CCR5 mutation; between 10 and 25\% of the population are believed to have at least one mutant CCR2 gene [2]. In a study of over $3000 \mathrm{HIV}$-positive people, those who had one mutant CCR2 gene developed AIDS two to four years later than people who had two normal copies of the CCR2 gene. The results were even more striking when the data on the effects of CCR2 and CCR5 mutations were combined. About $30 \%$ of long-term survivors who had been infected with HIV for at least 16 years or more without developing AIDS had at least one CCR2 or CCR5 mutant gene [10]. The protective effect of CCR2B-64I has also been demonstrated by other studies [1].

\section{Conclusions}

This study survey focused on a relatively small number of individuals. However, the findings contribute to the growing evidence that the presence and effects of genetic variants that have been understudied in the African population are still important when predicting hosts susceptibility to HIV-1 and progression to AIDS within the sub-Saharan African population and more so in our Kenyan population. The knowledge of this mechanism of HIV entry into cells has resulted in the development of a new class of ARVs entry inhibitors, aimed at blocking the CCR5, CCR2, or CXCR4 coreceptors.

\section{Conflict of Interests}

The authors declare that they have no competing interests.

\section{Authors' Contribution}

Dorcas Wachira and Samoel Ashimosi Khamadi conceived and designed the study. Raphael Lihana and Samoel Ashimosi Khamadi discussed and provided interpretation of the results.
Dorcas Wachira, Alex Maiyo, and Vincent Okoth wrote and revised the paper. All authors gave final approval of the paper to be published.

\section{Acknowledgments}

This study was carried out at Centre for Virus Research within Kenya Medical Research Institute. This study was funded in totality by funds generated by the HIV Research Laboratory. The authors thank the participating provincial and district hospitals together with the study participants for consenting to the use of their samples in this study. The authors would like to thank Dr. A. Wamachi, Dr. M. Warigia, and R. Omollo for their support in ensuring the study was carried out as planned.

\section{References}

[1] A. O. Anzala, T. B. Ball, T. Rostron et al., "CCR2-64I allele and genotype association with delayed AIDS progression in African women. University of Nairobi Collaboration for HIV Research," The Lancet, vol. 351, no. 9116, pp. 1632-1633, 1998.

[2] P. J. Easterbrook, T. Rostron, N. Ives, M. Troop, B. G. Gazzard, and S. L. Rowland-Jones, "Chemokine receptor polymorphisms and human immunodeficiency virus disease progression," The Journal of Infectious Diseases, vol. 180, no. 4, pp. 1096-1105, 1999.

[3] P. M. An, M. P. Martin, G. W. Nelson et al., "Influence of CCR5 promoter haplotypes on AIDS progression in African-Americans," AIDS, vol. 14, no. 14, pp. 2117-2122, 2000.

[4] E. Gonzalez, R. Dhanda, M. Bamshad et al., "Global survey of genetic variation in CCR5, RANTES, and MIP-1 $\alpha$ : impact on the epidemiology of the HIV-1 pandemic," Proceedings of the National Academy of Sciences of the United States of America, vol. 98, no. 9, pp. 5199-5204, 2001.

[5] G. S. Ryabov, E. V. Kazennova, and A. F. Bobkov, "Frequencies of the CCR2-64I and SDF1-3' A alleles associated with progression of the HIV-1 disease in healthy individuals from Moscow," Journal of Virology, vol. 38, pp. 278-280, 2002.

[6] J. Schinkel, M. Langendam, R. Coutinho, A. Krol, M. Brouwer, and Schuitemaker H, "No evidence for an effect of the CCR5 
delta32/+ and CCR2b 64I/+ mutations on human immunodeficiency virus (HIV)-1 disease progression among HIV-1-infected injecting drug users," The Journal of Infectious Diseases, vol. 179, no. 4, pp. 825-831, 1999.

[7] M. W. Smith, M. Dean, M. Carrington et al., "Contrasting genetic influence of CCR2 and CCR5 variants on HIV-1 infection and disease progression," Science, vol. 277, no. 5328, pp. 959-965, 1997.

[8] B. Su, G. Sun, D. Lu et al., "Distribution of three HIV-1 resistance-conferring polymorphisms (SDF1-3'A, CCR2-64I, and CCR5- $\triangle 32$ ) in global populations," European Journal of Human Genetics, vol. 8, no. 12, pp. 975-979, 2000.

[9] X. A. Angelina, G. S. Rogério, L. S. Juliana, and G.-C. Bernardo, "Distribution of the CCR2-64I allele in three Brazilian ethnic groups," Genetics and Molecular Biology, vol. 26, no. 3, pp. 241243, 2003.

[10] M. Marmor, K. Hertzmark, S. M. Thomas, P. N. Halkitis, and M. Vogler, "Resistance to HIV Infection," Journal of Urban Health, vol. 83, no. 1, pp. 5-17, 2006. 


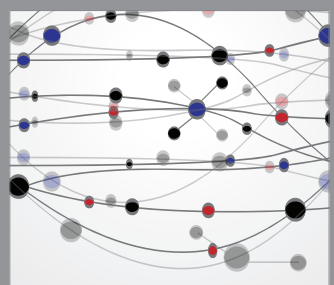

The Scientific World Journal
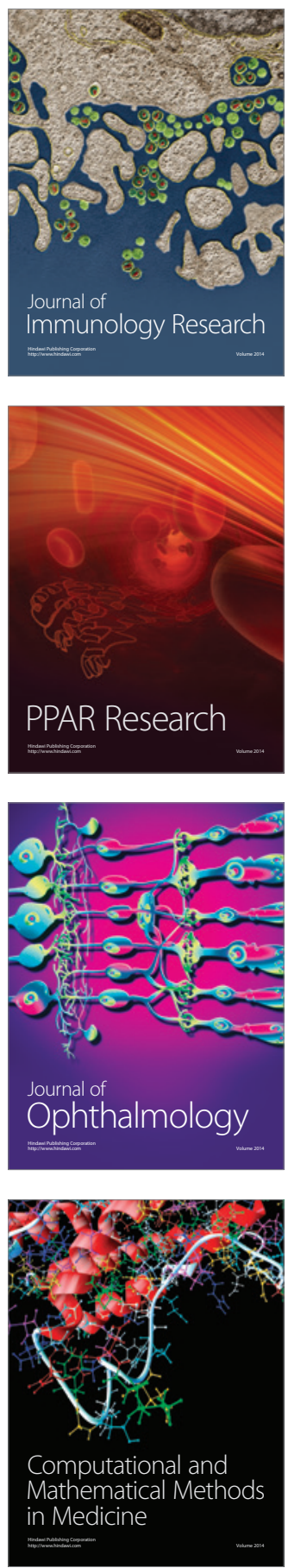

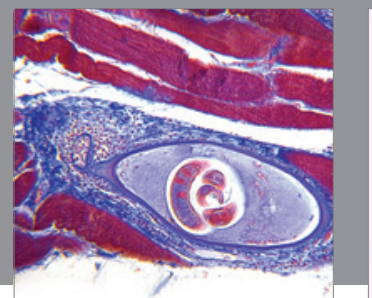

Gastroenterology

Research and Practice
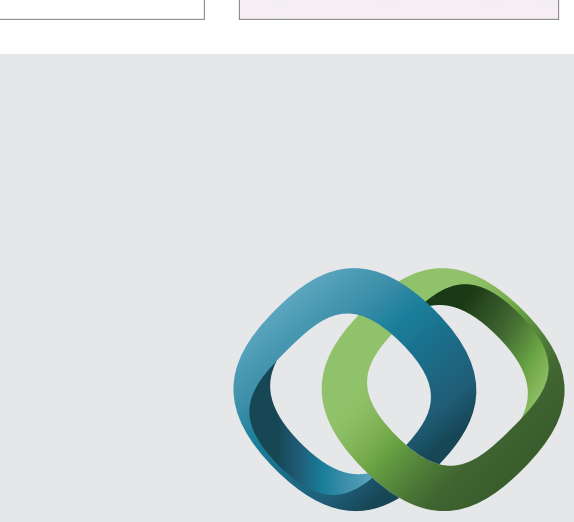

\section{Hindawi}

Submit your manuscripts at

http://www.hindawi.com
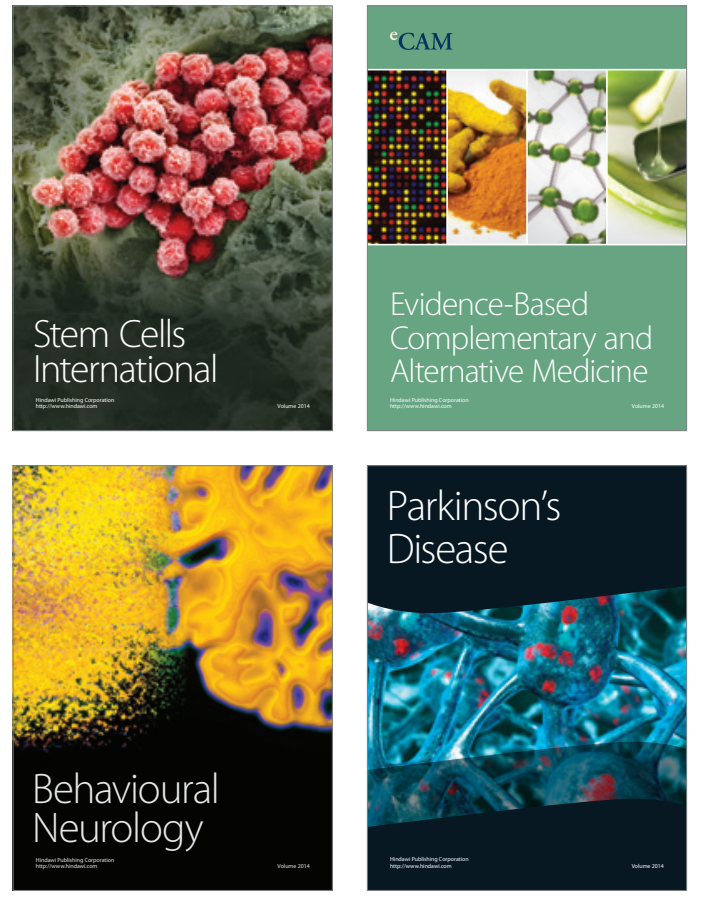
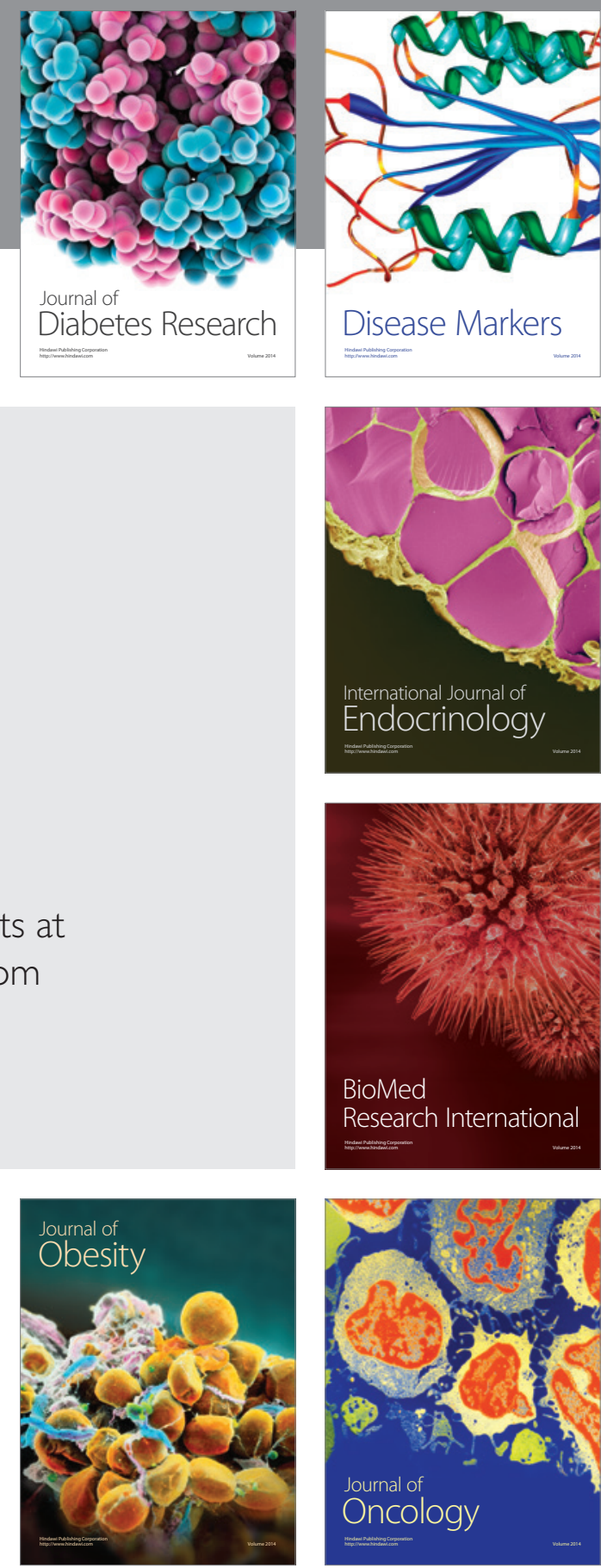

Disease Markers
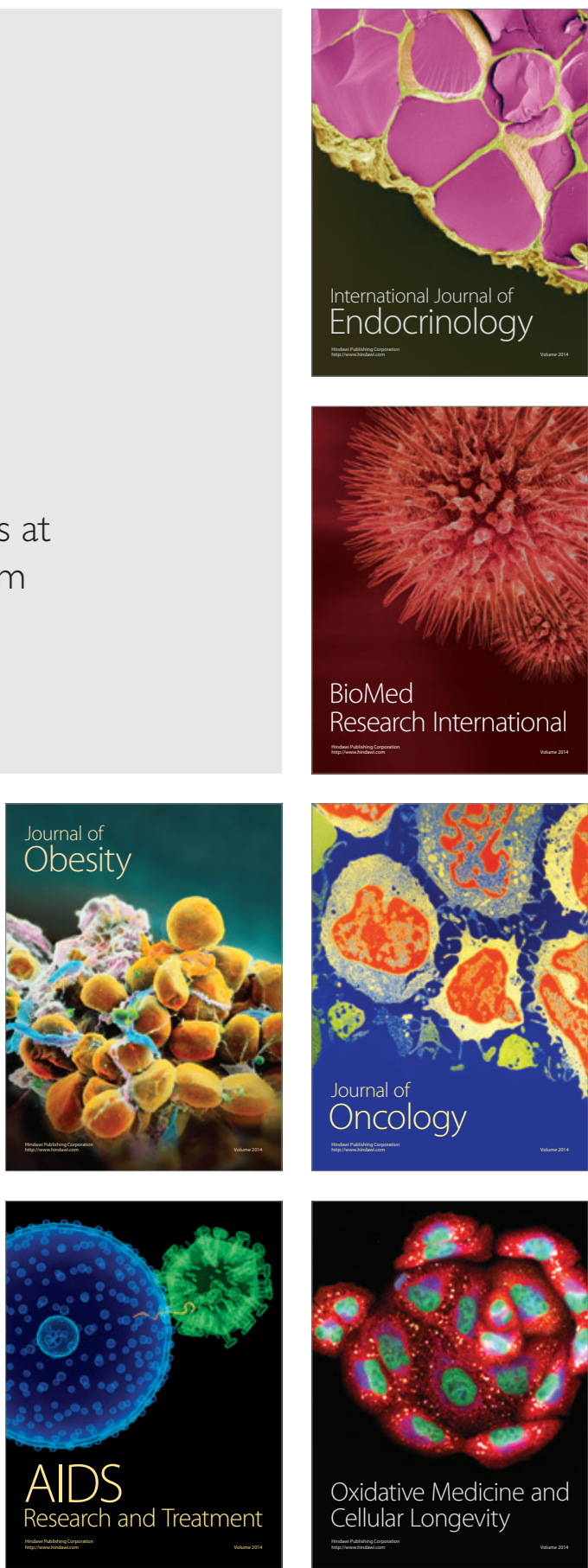